\title{
Antilisterial Bacteriocin from Lactobacillus rhamnosus CJNU 0519 Presenting a Narrow Antimicrobial Spectrum
}

\author{
Ye-Jin Jeong and Gi-Seong Moon* \\ Department of Biotechnology, Korea National University of Transportation, Jeungpyeong 368-701, Korea
}

\begin{abstract}
A lactic acid bacterium presenting antimicrobial activity against a Lactobacillus acidophilus strain used for eradication of acid inhibition was isolated from a natural cheese. The 16S rRNA gene sequence of the isolate best matched with a strain of L. rhamnosus and was designated L. rhamnosus CJNU 0519. The antimicrobial activity of the partially purified bacteriocin of CJNU 0519 was abolished when treated with a protease, indicating the protein nature of the bacteriocin. The partially purified bacteriocin (rhamnocin 519) displayed a narrow antimicrobial activity against L. acidophilus, Listeria monocytogenes, and Staphylococcus aureus among several tested bacterial and yeast strains. Rhamnocin 519 in particular showed strong bactericidal action against L. monocytogenes.
\end{abstract}

Key words: bacteriocin, Lactobacillus rhamnosus, narrow-range spectrum, Listeria monocytogenes, probiotics

\section{Introduction}

Bacteriocins are proteinaceous antimicrobial substances that inhibit the growth of closely related bacterial species (Drider et al., 2006; Klaenhammer, 1993). Bacteriocins produced from lactic acid bacteria (LAB) have been especially studied because of their safety. Many LAB bacteriocins have been identified and explored as food biopreservatives or antibiotic alternatives (Allen et al., 2014; Bali et al., 2014; Cui et al., 2012; Lohans and Vederas, 2012).

LAB bacteriocins are generally categorized into three classes (Nes and Holo, 2000). Class I (lantibiotics) contains post-translationally modified peptides having multiple thioether crosslinks formed by the addition of the thiols of cysteine to dehydroamino acids like dehydroalanine (from serine) and dehydrobutyrine (from threonine) (Yu et al., 2013). Nisin A and Z from Lactococcus lactis ssp. lactis is a representative Class I bacteriocin (Ward et al., 1994). Class II contains non-modified and heat-stable bacteriocins which are further divided into three subclasses: strong anti-listerial pediocin-like bacteriocins (subclass IIa), two-peptide bacteriocins (subclass IIb), and

\footnotetext{
*Corresponding author: Gi-Seong Moon, Department of Biotechnology, Korea National University of Transportation, Jeungpyeong 368-701, Korea. Tel: +82-43-820-5251, Fax: +82-43820-5272, E-mail: gsmoon@ut.ac.kr
}

other bacteriocins (subclass IIc) (Nes and Holo, 2000). Particularly, the pediocin family share consensus amino acid sequences between $40 \%$ to over $70 \%$ where YGNGV in the N-terminal sequence is highly conserved between the bacteriocins (Nes and Holo, 2000). Class III contains large heat-labile bacteriocins including helveticin $\mathrm{J}$ and enterolysin A (Joerger and Klaenhammer, 1990; Nilsen et al., 2003).

Among the identified bacteriocins, only nisin has been marketed (Lauková et al., 2014). Nisaplin is approved for use in over 50 countries (Lalpuria et al., 2013). Several bacteriocins including pediocin PA-1 are promising candidate for biopreservatives or antibiotic alternatives (Bali et al., 2014; Cotter et al., 2013; Mehta et al., 2013). Nevertheless, these bacteriocins mostly have a broad antimicrobial spectrum against gram-positive bacteria (Rodríguez et al., 2002; Ross et al., 1999). While this attribute helps to control a broad range of gram-positive pathogenic bacteria (Mehta et al., 2013), the bacteriocins can also inhibit beneficial gram-positive bacteria, such as LAB (Han et al., 2007; Kwon et al., 2002; Lee et al., 2002). Isolation of $\mathrm{LAB}$ bacteriocins capable of very targeting inhibition of, for example, food pathogens or spoilage bacteria, is desirable. Among Lactobacillus rhamnosus strains, L. rhamnosus strain 68 was confirmed to produce a bacteriocin rhamnosin A which was a small, heat-stable, and nonlanthionine-containing peptide and therefore categorized as a class II bacteriocin (Dimitrijević et al., 2009). 
Listeria monocytogenes and Staphylococcus aureus are representative food pathogenic bacteria (Gahan and Hill, 2014; Larkin et al., 2009). Particularly, L. monocytogenes is a psychrotrophic bacterium that grows at low temperature. Listeriosis outbreaks have been normally linked to consumption of milk products (Markkula et al., 2012; Rossi et al., 2008). L. monocytogenes is a threat to dairy food systems and effective control methods are needed. In this study, we isolated a LAB that produces a bacteriocin with a narrow antimicrobial spectrum that includes $L$. monocytogenes and $S$. aureus. Here we report the preliminary results.

\section{Materials and Methods}

\section{Bacterial strains and culture conditions}

Indicator strains were $L$. reuteri $\mathrm{KCTC} 3679$, L. casei CJNU 0588, L. acidophilus NCDO 955, Leuconostoc mesenteroides CJNU 0147, Pediococcus acidilactici K10, Enterococcus faecium MK3, Bacillus licheniformis 1-B12, L. monocytogenes KCTC 3569, S. aureus ATCC 14458, Escherichia coli $\mathrm{DH} 5 \alpha$, and Saccharomyces cerevisiae ATCC 24858. ATCC and KCTC strains were purchased from the American Type Culture Collection and Korean Collection for Type Cultures, respectively. LAB, L. monocytogenes, and $S$. aureus were cultured at $37^{\circ} \mathrm{C}$ with no agitation in MRS broth (De Man, Rogosa, and Sharpe) purchased from Difco (Sparks, MD, USA). B. subtilis and $E$. coli was cultured in nutrient broth (Difco) and LuriaBertani (LB) broth $(10 \mathrm{~g} / \mathrm{L}$ tryptone, $10 \mathrm{~g} / \mathrm{L} \mathrm{NaCl}$, and 5 $\mathrm{g} / \mathrm{L}$ yeast extract, $\mathrm{pH} 7.0$ ), respectively, at $37^{\circ} \mathrm{C}$ with shaking. S. cerevisiae was cultured in YPD broth (yeast extract $10 \mathrm{~g} / \mathrm{L}$, peptone $20 \mathrm{~g} / \mathrm{L}$, and dextrose $20 \mathrm{~g} / \mathrm{L}$ ) at $30^{\circ} \mathrm{C}$.

\section{Bacteriocin production assay}

Bacteriocin production by isolate CJNU 0519 was confirmed by a deferred antagonism assay for viable cells and spot-on-lawn assay for $\mathrm{pH}$-neutralized culture supernatant (Daeschel, 1992; Moon et al., 2000). Briefly, in the deferred antagonism assay, $1 \mu \mathrm{L}$ of the isolate culture was loaded on MRS agar and incubated for $12 \mathrm{~h}$ at $37^{\circ} \mathrm{C}$. Top agar $(0.7 \%, \mathrm{w} / \mathrm{v})$ seeded with $L$. acidophilus used for eradication of acid inhibition was overlaid on the agar and incubated for further $12 \mathrm{~h}$, and the inhibitory zone was examined. In the spot-on-lawn assay, the $\mathrm{pH}$ of the isolate culture was neutralized with $1 \mathrm{M} \mathrm{NaOH}$ and centrifuged at 5,000 $\mathrm{g}$ for $10 \mathrm{~min}$. The culture supernatant was filtered through $0.2 \mu \mathrm{m}$ syringe filters (Millipore, USA). The filtrate was concentrated with an acetone extraction method (Chung et al., 2011) and loaded onto a plate that had been overlaid with top agar seeded with L. acidophilus and incubated for $12 \mathrm{~h}$ at $37^{\circ} \mathrm{C}$. The concentrate was also treated with protease (Tokyo chemical, Japan), lipase (Tokyo chemical), and $\alpha$-amylase (Sigma-Aldrich, USA) for confirmation of proteinaceous antimicrobial peptide (bacteriocin).

\section{Isolate identification}

The 16S rRNA gene sequence of CJNU 0519 was analyzed for bacterial identification. The strain was overnight cultured in MRS broth and sent to Macrogen (Korea) for the 16S rRNA gene sequence analysis. The gene sequence was aligned and homology search was performed by a BLAST program (http://www.ncbi.nlm.nih.gov/).

\section{Preparation of partially purified bacteriocin}

Partially purified bacteriocin was prepared using the acetone extraction method (Chung et al., 2011). As above mentioned, an overnight culture of CJNU 0519 was neutralized with $1 \mathrm{M} \mathrm{NaOH}$, centrifuged at $5000 \mathrm{~g}$ for 10 min, and filtered. The culture supernatant was mixed with acetone at a ratio of $1: 3$ and stored at $-20^{\circ} \mathrm{C}$ for $3 \mathrm{~h}$. The mixture was centrifuged at $5000 \mathrm{~g}$ for $15 \mathrm{~min}$. The supernatant was recovered and evaporated with a rotary evaporator. The partially purified bacteriocin was stored at $-20^{\circ} \mathrm{C}$ until use. The bacteriocin activity expressed as arbitrary units $(\mathrm{AU}) / \mathrm{mL}$ was defined as the reciprocal of the highest two-fold dilution showing an inhibition zone (Daeschel, 1992).

\section{Antimicrobial spectrum}

The antimicrobial spectrum of L. rhamnosus CJNU 0519 cells and the partially purified bacteriocin (rhamnocin 519) was investigated using the aforementioned bacteriocin assays. Indicators were the gram-positive bacteria $L$. reuteri $\mathrm{KCTC} 3679$, L. casei CJNU 0588, L. acidophilus NCDO 955, L. mesenteroides CJNU 0147, P. acidilactici $\mathrm{K} 10$, E. faecium MK3, B. licheniformis 1-B-12, L. monocytogenes KCTC 3569, and S. aureus ATCC 14458; gram-negative bacterium E. coli $\mathrm{DH} 5 \alpha$; and yeast $S$. cerevisiae ATCC 24858.

\section{Action mode of rhamnocin 519}

An overnight culture of $L$. monocytogenes KCTC 3569 was inoculated in $5 \mathrm{~mL}$ of peptone water $(0.1 \%$, w/v) and cultured at $37^{\circ} \mathrm{C}$ for $21 \mathrm{~h}$. At $3 \mathrm{~h}, 150$ and $300 \mathrm{AU} / \mathrm{mL}$ of partially purified rhamnocin 519 were added into the inoculum, respectively. The viable cell count of $L$. monocyt- 


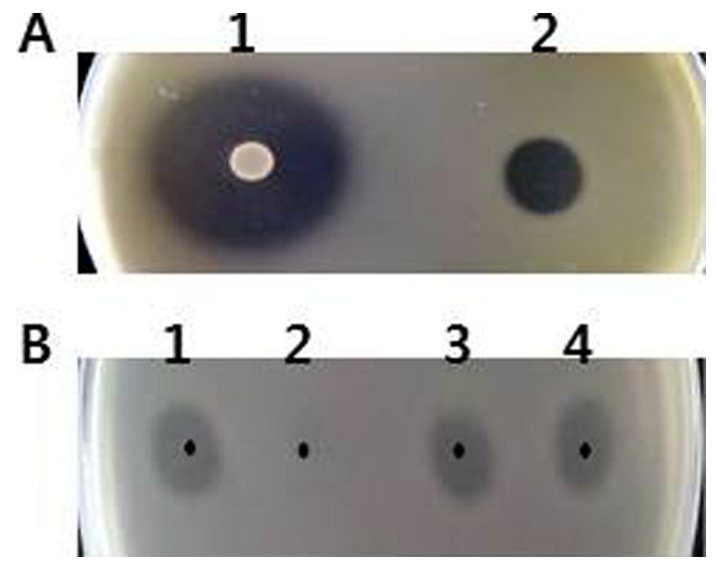

Fig. 1. Bacteriocin activity of lactic acid bacterium strain CJNU 0519. A. Deferred antagonism assay (1) for viable cells and spot-on-lawn assay (2) for concentrated partially purified bacteriocin. B. Spot-on-lawn assay for concentrated partially purified bacteriocin (1) and the bacteriocin treated with protease (2), lipase (3), and $\alpha$-amylase. Lactobacillus acidophilus was used as the indicator.

ogenes was analyzed on MRS agar plates at intervals.

\section{Results and Discussion}

\section{Bacteriocin production from CJNU 0519}

LAB CJNU 0519 isolated from a natural cheese was confirmed to produce a bacteriocin using the deferred antagonism assay for viable cells and spot-on-lawn assay for the partially purified bacteriocin. As shown in Fig. 1, CJNU 0519 viable cells presented inhibition zone against L. acidophilus used for eradication of acid inhibition, and the partially purified bacteriocin also showed antimicrobial activity against the indicator strain. The bacteriocin was treated with protease, lipase, and $\alpha$-amylase. Protease abolished the antimicrobial activity of the bacteriocin, indicating its proteinaceous nature. LAB can produce antimicrobial substances including organic acids and hydrogen peroxide, as well as bacteriocins (Pawlowska et al., 2012). Therefore, it is a prerequisite to check whether the antimicrobial activity of an isolate is caused by a bacteriocin.

\section{Identification of CJNU 0519}

The 16S rRNA gene sequence of CJNU 0519 was analyzed for bacterial identification. The gene sequence was aligned and homology search was performed. The sequence best matched (99\% identity) that of L. rhamnosus ATCC 8530 (GenBank accession no., CP003 094.1). The isolate was designated L. rhamnosus CJNU 0519. The bacteriocin produced from L. rhamnosus CJNU 0519 was designated rhamnocin 519. A phylogenetic tree based on $16 \mathrm{~S}$ rRNA gene sequences of CJNU 0519 and related type strains was shown in Fig. 2.

\section{Antimicrobial spectra of $L$. rhamnosus CJNU 0519 and rhamnocin 519}

The antimicrobial spectra of L. rhamnosus CJNU 0519

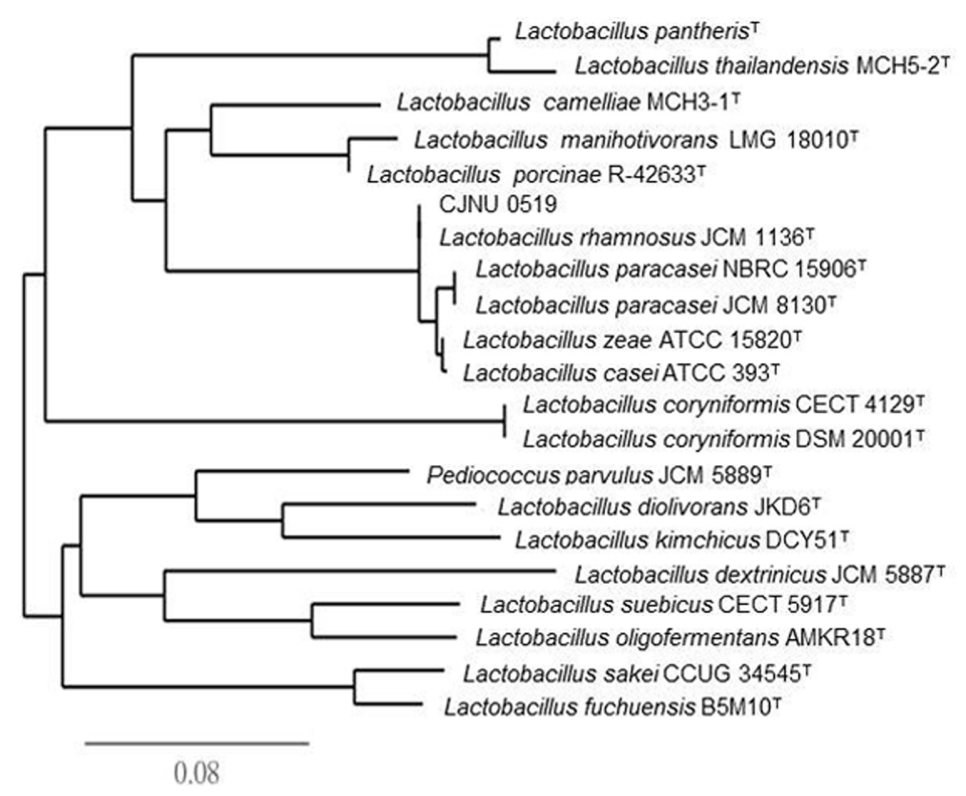

Fig. 2. Phylogenetic tree derived from 16S rRNA gene sequences of CJNU 0519 and related type strains. The branch length is proportional to the number of substitutions per site and the tree was constructed based on an algorithm from http://phylogeny.lirmm.fr. 
Table 1. Antimicrobial spectrum of $L$. rhamnosus CJNU 0519 cells and partially purified rhamnocin 519

\begin{tabular}{|c|c|c|c|c|}
\hline \multicolumn{3}{|c|}{ Target strain } & $\begin{array}{c}\text { Deferred antagonism } \\
\text { assay }\end{array}$ & $\begin{array}{c}\begin{array}{c}\text { Spot-on-lawn } \\
\text { assay }^{2)}\end{array} \\
\text { (a) }\end{array}$ \\
\hline \multirow{9}{*}{ Gram-positive } & \multirow{6}{*}{ Lactic acid bacteria } & Lactobacillus reuteri KCTC 3679 & - & - \\
\hline & & Lactobacillus casei CJNU 0588 & - & - \\
\hline & & Lactobacillus acidophilus NCDO 955 & + & + \\
\hline & & Leuconostoc mesenteroides CJNU 0147 & - & - \\
\hline & & Pediococcus acidilactici $\mathrm{K} 10$ & + & - \\
\hline & & Enterococcus faecium MK3 & - & - \\
\hline & Bacillus & B. licheniformis 1-B-12 & + & - \\
\hline & \multirow{2}{*}{ Pathogenic bacteria } & Listeria monocytogenes KCTC 3569 & + & + \\
\hline & & Staphylococcus aureus ATCC 14458 & + & + \\
\hline Gram-negative & & Escherichia coli DH5 $\alpha$ & - & - \\
\hline Yeast & & Saccharomyces cerevisiae ATCC 24858 & - & - \\
\hline
\end{tabular}

${ }^{10}$ Deferred antagonism assay for L. rhamnosus CJNU 0519 cells.

${ }^{2)}$ Spot on the lawn assay for partially purified rhamnocin 519 .

cells and partially purified rhamnocin 519 was investigated against several gram-positive bacteria, gram-negative bacteria, and yeast. L. rhamnosus CJNU 0519 cells inhibited the growth of $L$. acidophilus NCDO 955, P. acidilactici $\mathrm{K} 10$, B. licheniformis 1-B-12, L. monocytogenes KCTC 3569, and $S$. aureus ATCC 14458, while the partially purified rhamnocin 519 inhibited L. acidophilus NCDO 955, L. monocytogenes KCTC 3569, and $S$. aureus ATCC 14458 (Table 1). The inhibitory effect of $L$. rhamnosus CJNU 0519 cells on the growth of $P$. acidilactici $\mathrm{K} 10$ and $B$. licheniformis 1-B-12 might be due to organic acids from the cells. Rhamnocin 519 has a narrow antimicrobial spectrum, which could be exploited to control food-borne pathogenesis caused by L. monocytogenes or $S$. aureus. This selective targeting could minimalize the growth inhibition of beneficial bacteria for human health including LAB. Effects of broad- and narrow-range antimicrobials on enteropathogenic Clostridium difficile and microbial diversity in a model of the human distal colon have been compared (Rea et al., 2011). In the study, broad-range antimicrobials including vancomycin, metronidazole, and the bacteriocin lacticin 3147 significantly reduced the viable numbers of $C$. difficile and other members of the human gut microbiota. The narrow-range antimicrobial bacteriocin thuricin CD produced by $B$. thuringiensis also significantly decreased $C$. difficile viability, but had no significant impact on microbial composition. The study highlighted the value of narrow-range antimicrobial bacteriocins and their potential as biopreservatives or antibiotic alternatives.

\section{Action mode of rhamnocin 519}

Action mode of rhamnocin 519 was presented in Fig. 3. Partially purified rhamnocin 519 (150 and $300 \mathrm{AU} / \mathrm{mL}$ )

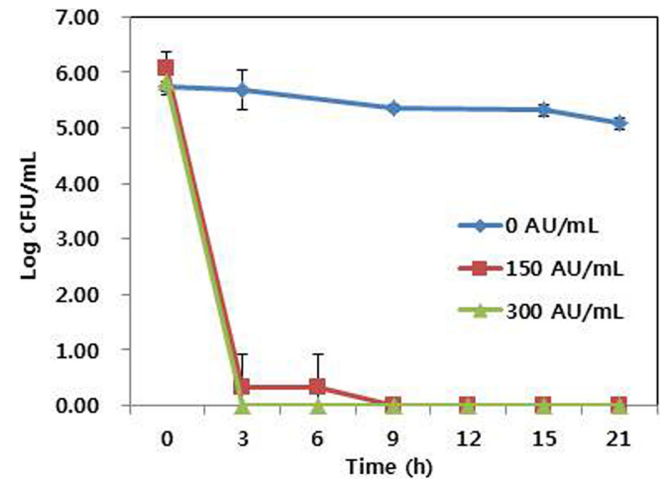

Fig. 3. Action mode of partially purified rhamnocin 519 against Listeria monocytogenes. Abbreviations: $0 \mathrm{AU} / \mathrm{mL}$, L. monocytogenes was inoculated in peptone water $(10 \%$, $\mathrm{w} / \mathrm{v}) ; 150$ and $300 \mathrm{AU} / \mathrm{mL}, 150$ and $300 \mathrm{AU} / \mathrm{mL}$ of partially purified rhamnocin was added to the inoculum, respectively at $3 \mathrm{~h}$. The values are presented as mean \pm SD.

was added to $5 \mathrm{~mL}$ of peptone water $(10 \%$, w/v) previously inoculated with an overnight culture of $L$. monocytogenes KCTC 3569. Before the addition of rhamnocin 519 , the initial viable counts of $L$. monocytogenes were almost the same between samples. Subsequently, significant decreases were evident at $3 \mathrm{~h}$ in the bacteriocin containing samples. The initial cell count of bacteriocin-free sample was 5.75 Log colony forming units $(\mathrm{CFU}) / \mathrm{mL}$ and reached 5.08 Log CFU/mL at $21 \mathrm{~h}$. Similarly, the initial cell count of sample containing $150 \mathrm{AU} / \mathrm{mL}$ rhamnocin 519 was $6.06 \mathrm{Log} \mathrm{CFU} / \mathrm{mL}$, with a decrease to 0.33 $\log \mathrm{CFU} / \mathrm{mL}$ at $3 \mathrm{~h}$ and no detectable viable cells at $9 \mathrm{~h}$. The initial cell count of sample containing $300 \mathrm{AU} / \mathrm{mL}$ rhamnocin 519 was $5.84 \log \mathrm{CFU} / \mathrm{mL}$, with no viable cells detected at $3 \mathrm{~h}$. These results indicate a potent anti- 
listerial activity of rhamnocin 519; the activity is consistent with categorization as a Class IIa bacteriocin (Nes and Holo, 2000).

LAB bacteriocins are of interest because of their safety and antimicrobial potential against food-borne pathogens and spoilage bacteria. Many LAB bacteriocins have been identified and explored as food biopreservatives or antibiotic alternatives (Allen et al., 2014; Bali et al., 2014; Cui et al., 2012; Lohans and Vederas, 2012). Most bacteriocins have a broad-range antimicrobial spectrum, which can deleteriously influence the human gut microbiota and inhibit bacteria that are beneficial for human health (Rea et al., 2011). Bacteriocins with a narrow antimicrobial spectrum against specific food-borne pathogens or spoilage bacteria could be more promising therapeutic agents or natural preservatives.

In this study, the novel LAB, L. rhamnosus CJNU 0519, was shown to produce the bacteriocin rhamnocin 519, which displayed a narrow antimicrobial spectrum that included L. monocytogenes and S. aureus. Particularly, rhamnocin 519 strongly inhibited the growth of L. monocytogenes highlighting the potential of L. rhamnosus CJNU 0519 in the control of food-borne pathogens. Additionally, rhamnocin 519 could be a promising candidate biopreservative or antibiotic alternative. Further analyses, such as optimal culture condition for bacteriocin mass production, biochemical properties of rhamnocin 519, and identification of corresponding genes for the bacteriocin production, will be performed in the near future.

\section{Acknowledgements}

The authors thank to Mr. Jung-Mo Yang for technical support.

\section{References}

1. Allen, H. K., Trachsel, J., Looft, T., and Casey, T. A. (2014) Finding alternatives to antibiotics. Ann. N. Y. Acad. Sci. 323, 91-100.

2. Bali, V., Panesar, P. S., and Bera, M. B. (2014) Trends in utilization of agro-industrial byproducts for production of bacteriocins and their biopreservative applications. Crit. Rev. Biotechnol. [Epub ahead of print]

3. Bali, V., Panesar, P. S., Bera, M. B., and Kennedy, J. F. (2014) Bacteriocins: recent trends and potential applications. Crit. Rev. Food Sci. Nutr. [Epub ahead of print]

4. Chung, D. M., Kim, K. E., Jeong, S. Y., Park, C. S., Ahn, K. H., Kim, D. H., Kang, D. O., Chun, H. K., Yoon, B. D., Koh, H. B., Kim, H. J., and Choi, N. S. (2011) Rapid concentration of some bacteriocin-like compounds using an organic solvent. Food Sci. Biotechnol. 20, 1457-1459.

5. Cotter, P. D., Ross, R. P., and Hill, C. (2013) Bacteriocins - a viable alternative to antibiotics? Nat. Rev. Microbiol. 11, 95105.

6. Cui, Y., Zhang, C., Wang, Y., Shi, J., Zhang, L., Ding, Z., Qu, X., and Cui, H. (2012) Class IIa bacteriocins: diversity and new developments. Int. J. Mol. Sci. 13, 16668-16707.

7. Daeschel, M. A. (1992) Procedures to detect antimicrobial activities of microorganisms. In: Food biopreservatives of microbial origin. Ray, B. and Daeschel, M. (eds) CRC Press, FL, pp. 57-80.

8. Dimitrijević, R., Stojanović, M., Zivković, I., Petersen, A., Jankov, R. M., Dimitrijević, L., and Gavrović-Jankulović, M. (2009) The identification of a low molecular mass bacteriocin, rhamnosin A, produced by Lactobacillus rhamnosus strain 68. J. Appl. Microbiol. 107, 2108-2115.

9. Drider, D., Fimland, G., Héchard, Y., McMullen, L. M., and Prévost, H. (2006) The continuing story of class IIa bacteriocins. Microbiol. Mol. Biol. Rev. 70, 564-582.

10. Gahan, C. G. and Hill, C. (2014) Listeria monocytogenes: survival and adaptation in the gastrointestinal tract. Front Cell Infect. Microbiol. 4, 9.

11. Han, K. S., Kim, Y., Kim, S. H., and Oh, S. (2007) Characterization and purification of acidocin $1 \mathrm{~B}$, a bacteriocin produced by Lactobacillus acidophilus GP1B. J. Microbiol. Biotechnol. 17, 774-783.

12. Joerger, M. C. and Klaenhammer, T. R. (1990) Cloning, expression, and nucleotide sequence of the Lactobacillus helveticus 481 gene encoding the bacteriocin helveticin J. J. Bacteriol. 172, 6339-6347.

13. Klaenhammer, T. R. (1993) Genetics of bacteriocins produced by lactic acid bacteria. FEMS Microbiol. Rev. 12, 3986.

14. Kwon, D. Y., Koo, M. S., Ryoo, C. R., Kang, C. H., Min, K. H., and Kim, W. J. (2002) Bacteriocin produced by Pediococcus sp. in kimchi and its characteristics. J. Microbiol. Biotechnol. 12, 96-105.

15. Lalpuria, M., Karwa, V., Anantheswaran, R. C., and Floros, J. D. (2013) Modified agar diffusion bioassay for better quantification of Nisaplin ${ }^{\circledR}$. J. Appl. Microbiol. 114, 663-671.

16. Larkin, E. A., Carman, R. J., Krakauer, T., and Stiles, B. G. (2009) Staphylococcus aureus: the toxic presence of a pathogen extraordinaire. Curr. Med. Chem. 16, 4003-4019.

17. Lauková, A., Chrastinová, L., Plachá, I., Kandrièáková, A., Szabóová, R., Strompfová, V., Chrenková, M., Cobanová, K., and Zitòan, R. (2014) Beneficial effect of lantibiotic nisin in rabbit husbandry. Probiotics Antimicrob. Proteins 6, 4146.

18. Lee, K. H., Moon, G. S., An, J. Y., Lee, H. J., Chang, H. C., Chung, D. K., Lee, J. H., and Kim, J. H. (2002) Isolation of a nisin-producing Lactococcus lactis strain from kimchi and characterization of its nisZ gene. J. Microbiol. Biotechnol. 12, 389-397.

19. Lohans, C. T. and Vederas, J. C. (2012) Development of class IIa bacteriocins as therapeutic agents. Int. J. Microbiol. 2012, 
386-410.

20. Markkula, A., Mattila, M., Lindström, M., and Korkeala, H. (2012) Genes encoding putative DEAD-box RNA helicases in Listeria monocytogenes EGD-e are needed for growth and motility at $3^{\circ} \mathrm{C}$. Environ. Microbiol. 14, 2223-2232.

21. Mehta, R., Arya, R., Goyal, K., Singh, M., and Sharma, A. K. (2013) Bio-preservative and therapeutic potential of pediocin: recent trends and future perspectives. Recent Pat. Biotechnol. 7, 172-178.

22. Moon, G. S., Jeong, J. J., Ji, G. E., Kim, J. S., and Kim, J. H. (2000) Characterization of a bacteriocin produced by Enterococcus sp. T7 isolated from humans. J. Microbiol. Biotechnol. 10, 507-513.

23. Nes, I. F. and Holo, H. (2000) Class II antimicrobial peptides from lactic acid bacteria. Biopolymers 55, 50-61.

24. Nilsen, T., Nes, I. F., and Holo, H. (2003) Enterolysin A, a cell wall-degrading bacteriocin from Enterococcus faecalis LMG 2333. Appl. Environ. Microbiol. 69, 2975-2984.

25. Pawlowska, A. M., Zannini, E., Coffey, A., and Arendt, E. K. (2012) "Green preservatives": combating fungi in the food and feed industry by applying antifungal lactic acid bacteria. Adv. Food Nutr. Res. 66, 217-238.

26. Rea, M. C., Dobson, A., O'Sullivan, O., Crispie, F., Fouhy, F., Cotter, P. D., Shanahan, F., Kiely, B., Hill, C., and Ross, R. P.
(2011) Effect of broad- and narrow-spectrum antimicrobials on Clostridium difficile and microbial diversity in a model of the distal colon. Proc. Natl. Acad. Sci. USA 108 Suppl. 1, 4639-4644.

27. Rodríguez, J. M., Martínez, M. I., and Kok, J. (2002) Pediocin PA-1, a wide-spectrum bacteriocin from lactic acid bacteria. Crit. Rev. Food Sci. Nutr. 42, 91-121.

28. Ross, R. P., Galvin, M., McAuliffe, O., Morgan, S. M., Ryan, M. P., Twomey, D. P., Meaney, W. J., and Hill, C. (1999) Developing applications for lactococcal bacteriocins. Antonie Van Leeuwenhoek 76, 337-346.

29. Rossi, M. L., Paiva, A., Tornese, M., Chianelli, S., and Troncoso, A. (2008) Listeria monocytogenes outbreaks: a review of the routes that favor bacterial presence. Rev. Chilena Infectol. 25, 328-335.

30. Yu, Y., Zhang, Q., and van der Donk, W. A. (2013) Insights into the evolution of lanthipeptide biosynthesis. Protein Sci. 22, 1478-1489.

31. Ward, L. J., Brown, J. C., and Davey, G. P. (1994) Application of the ligase chain reaction to the detection of nisinA and nisinZ genes in Lactococcus lactis ssp. lactis. FEMS Microbiol. Lett. 117, 29-33.

(Received 2015.1.14/Accepted 2015.1.27) 